\title{
Lima Barreto dialoga com a concepção de arte de Leon Tolstói
}

\author{
Maria Salete Magnoni
}

Resumo No diálogo estabelecido entre Lima Barreto e Leon Tolstói, a autora mostra como a concepção de arte defendida pelo romancista russo está presente no projeto literário elaborado pelo escritor brasileiro. Palavras-chave arte " herança cultural " Lima Barreto " Leon Tolstói.

Abstract From the dialogue established between Lima Barreto and Leon Tostoy, the author shows how the conception of art defended by Tostoy is present in the literary project of Lima Barreto. Key words art" cultural heritage " Lima Barreto " Leon Tostoy. 
Na historiografia literária brasileira do início do século xx, é comum encontrarmos referências acerca da influência das idéias do escritor russo Leon Tolstói sobre os literatos brasileiros. Vários são os escritores apontados pelos críticos e historiadores de nossa literatura que teriam criado obras sob a inspiração tolstoiana. ${ }^{1}$ Esse apreço pelo autor de Ana Karenina "conjugou-se com as atividades anarquistas e socialistas aqui verificadas nas duas primeiras décadas do século; [...] no '1900' o anarquismo foi para muita gente apenas 'literatura'. E era Tolstói o paradigma desses reformadores utópicos".2

Dentre esse grupo de escritores ditos tolstoianos, um deles, o mais expressivo, aliás, do período que se convencionou chamar Pré-modernismo, incorporou na sua produção literária muito mais do que a mera forma panfletária de propaganda do ideário anarco-cristão de Leon Tolstói.3 Refiro-me a Afonso Henriques de Lima Barreto. A herança recebida de Tolstói por Lima Barreto reside, na minha opinião, na concepção de Arte postulada pelo escritor russo, explícita no polêmico livro O que é a Arte?. Publicado em 1897, provocou um grande debate entre a intelectualidade e os artistas em geral, pois os conceitos ali apresentados estavam na contramão de outro muito caro aos artistas do final do século XIX: o da autonomia. Mas também por trazer à tona um outro questionamento em relação à arte que continua pertinente: o de "determinar sua função, sua relação com a sociedade" 4 .

1 BROCA, Brito. A vida literária no Brasil - 1900. Rio de Janeiro: José Olympio, 1960, p. 116-20; CARVALHO, Elísio de. As modernas correntes estéticas na literatura brasileira. Rio de Janeiro: Garnier, 1907, p. 77-98; BARBOSA, Francisco de Assis. A vida de Lima Barreto. Belo Horizonte/Sāo Paulo: Itatiaia/Edusp, 1988, p. 127-8; CANDIDO, Antonio. Teresina etc. São Paulo: Paz e Terra, 1992, p. 77-81; PEREIRA, Lúcia Miguel. História da literatura brasileira: prosa de ficçāo (1870 a 1920). Belo Horizonte/ São Paulo: Itatiaia/ Edusp, 1988 , p. 234-6.

2 BROCA, Brito. Ibidem, p. 116-7.

3 Porém, essa idéia a respeito da obra de Tolstói precisa ser vista com muito cuidado para não se cometer injustiça. Tido como um dos grandes nomes da literatura universal, escreveu romances, contos e novelas de elevado nivel de elaboraçāo intelectual e artística. Há que se destacar apenas o romance Ressurreição, escrito já quase no final de sua vida, este sim, com a clara intençāo de propagandear suas reflexōes filosóficas e religiosas. Para maiores informaçōes ver: wooDcock, George. Anarquismo: uma história das idéias e movimentos libertários. (Trad. de Júlia Tettamanzy), Porto Alegre: LP\&M, 1983, V. 1, p. 196-208

4 FABRIS, Annateresa. A teoria estética de Tolstói. In: TOLSTOI, Leon. O que é a Arte? (trad. Yolanda S. de Toledo e Yun Jung Im). Săo Paulo: Experimento, 1994, p. 18. 
A exposição que se segue acerca das convicções de Leon Tolstói sobre arte, julgo-a necessária para fundamentar a hipótese a respeito da herança presente na obra barretiana.

Questionando as várias definições existentes sobre a arte, Tolstói não apenas se contrapõe a todas elas como formula a sua própria definição, considerando ser a real função da arte na sociedade a de instrumento de comunicação e ligação entre os homens:

Enganam-se os metafísicos que vêem na arte a revelação de uma idéia misteriosa da beleza ou de Deus. Tampouco é a arte, como querem os estetas fisiologistas, uma atividade lúdica na qual o homem despende seu excedente de energia. Não é a produção de objetos agradáveis; não é, acima de tudo, um prazer; é um meio de reunir os homens angariando-os pela unidade de sentimentos e, portanto, indispensáveis [sic] à vida da humanidade e ao seu progresso no caminho da felicidade. 5

Toda obra artística obtém o efeito de pôr aqueles que lhe experimentaram o fascínio em comunicação com aquele que foi seu autor e com todos aqueles que, antes ou depois, foram ou serão seus participantes. A arte age como a palavra que serve de ligação entre os homens, transmitindo-lhes o pensamento, lá onde por meio da arte, são comunicados pensamentos e emoções. A peculiaridade deste último meio de intercurso, distinguindoo do intercurso por meio de palavras, consiste nisto: enquanto por palavras um homem transmite seus pensamentos a um outro, pela arte ele transmite seus sentimentos. ${ }^{6}$

Analisando a recepção da arte na sociedade sua contemporânea, Tolstói afirma que não só a capacidade de se distinguir entre a boa e a má arte fora perdida, mas também a própria percepção do que era arte. Desenvolve a partir dessa constatação a noção do contágio artístico como forma de distinção entre a verdadeira e a falsa arte.

Existe, apesar de tudo, um sinal certo e infalível para distinguir arte verdadeira de sua contrafação; é aquilo que chamamos de contágio artístico. Se um homem, sem nenhum esforço de sua parte, perante a obra de outro homem, experimenta uma emoção que une aquele a outros, que, contemporaneamente, receberiam a mesma impressão, isto significa que a obra diante da qual se encontra é obra de arte. E uma obra pode ser tão bela quanto se queira poética, rica em efeitos e interessante, mas não será obra de arte se não despertar em nós aquela emoção muito particular, a alegria de nos sentirmos em comunhão com o autor e com outros homens em companhia dos quais lemos, contemplamos ou ouvimos a obra em questão.7

5 TOLSTÓ, Leon. O que é a Arte? Ibidem, p. 51.

6 lbidem, p. 50.

7 lbidem, p. 119.

$208 \neg$ Maria Salete Magnoni 
Quanto maior o poder de contágio, maior é o poder de comunicação; quanto mais forte for a comunicação, mais verdadeira é a arte. São três as condições básicas que determinam o grau de comunicação da arte: singularidade dos sentimentos expressos, clareza de expressão e sinceridade da emoção transmitida. A singularidade dos sentimentos garante maior ação sobre quem os recebe. Já a clareza de expressão dos sentimentos é o que possibilita a sensação de estarmos unidos ao artista. A satisfação de quem vivencia tal experiência é ainda maior se os sentimentos expressos são aqueles existentes já há algum tempo e que finalmente encontraram um canal de expressão. Mas a fundamental entre as três condições é a sinceridade:

Acima de tudo, porém, é o grau de sinceridade do artista que determina o grau de contágio artístico. Quando o espectador, ouvinte ou o leitor sentem que o próprio artista se comove com sua obra, que ele escreve, pinta ou toca para si próprio, assimila $[s i c]$ repentinamente os sentimentos do artista. E, ao contrário, quando o espectador, ouvinte ou leitor percebem que o autor não produz a obra para si próprio, nem experimenta pessoalmente o que deseja expressar, prontamente nasce neles um desejo de resistência. Em tal caso nem a novidade do sentimento nem a simplicidade da expressão conseguem transmitir-lhes a expressão desejada. ${ }^{8}$

Portanto, para Tolstói, a sinceridade é condição essencial da arte, afirmando ainda ser a arte popular a principal portadora dessa condição, pois a arte feita pelas classes superiores raramente atinge essa qualidade por estar mediada pela profissionalização, pela possibilidade de lucro ou pelo amor-próprio do artista.

Enfim, são essas as pistas para se distinguir entre a verdadeira arte e a contrafação e para medir a qualidade da arte enquanto arte:

A ausência de qualquer uma dessas condições exclui a obra da categoria da arte e a relega à da contrafação da arte. Se a obra não transmite a peculiaridade do sentimento do artista e é portanto não individual, se está expresso de forma não inteligível, ou se não procedeu da necessidade interior do autor pela expressão, não é uma obra de arte. Se todas essas condições estão presentes mesmo em mínimos graus, então a obra, mesmo que seja fraca, é ainda uma obra de arte. ${ }^{9}$

A arte do futuro, na nova sociedade vislumbrada por Tolstói com base nos seus ideais, deixará de ser mercadoria e de expressar sentimentos acessíveis somente a um seleto grupo social, passando a desempenhar o seu verdadeiro 
papel, que é o de estabelecer, através dos sentimentos, a comunicação entre os homens em busca da fraternidade universal:

No futuro não será considerada arte senão aquela que expressar os sentimentos que impelirem $[s i c]$ os homens à união fraterna, ou mesmo sentimentos tão universais que podem ser experimentados pelas raças humanas. Apenas essa arte será assinalada entre todas, admitida, encorajada e difundida. ${ }^{10}$

Diante de tal concepção de arte, o artista também terá redefinido o seu papel. Não será o ser "eleito", elevado a tal condição e nem receberá pelo seu trabalho. Será artista, independentemente da sua origem social, todo aquele que sentir necessidade e for capaz de realizar o ato da criação. $\mathrm{O}$ artista do futuro não produzirá distanciado da realidade cotidiana; isso seria prejudicial a sua capacidade de produção artística. O distanciamento das condições comuns a todos os homens "retira-lhe a ocasião e a possibilidade de aprender a tomar conhecimento dos sentimentos mais importantes e naturais do homem"."11

A arte, por permitir a re-ligação dos homens, é também vista como expressão da consciência religiosa. Tolstói atribui-lhe, assim, um papel decisivo para a construção da sociedade do futuro:

A tarefa da arte é enorme. Através da influência da verdadeira arte, auxiliada pela ciência, guiada pela religião, aquela cooperação pacífica do homem que é agora mantida por meios externos - pelas nossas cortes judiciais, polícia, instituições de caridade, inspeções de fábricas, e assim por diante - deveria ser obtida pela atividade livre e alegre dos homens. A arte deveria fazer com que a violência fosse posta de lado.

E é somente a arte que pode alcançar isso.

Só a arte pode conseguir que sentimentos de amor e fraternidade, hoje acessiveis somente aos melhores de nossa sociedade, venham a ser sentimentos constantes, universais, instintivos em todos os homens. Estimulando, com o auxílio de criações imaginárias, sentimentos de fraternidade e amor, podem-se habituar os homens a experimentá-los na realidade. Podem-se assentar trilhos na alma humana sobre os quais daí em diante passe a vida, sob a direção da ciência e da religião.

E, uma vez unidos os mais diversos homens em comunidade de sentimentos, suprimidas as distinções entre eles, a arte universal pode ser o preparo para uma união definitiva. Poderá demonstrar aos homens, não por meio do raciocínio mas por meio da própria vida, a alegria da união universal ultrapassando as barreiras impostas pela vida. ${ }^{12}$

10 lbidem, p. 147.

11 Ibidem, p. 149

12 Ibidem, p. 160

$210 \neg$ Maria Salete Magnoni 
Certa ocasião Lima Barreto, numa carta em que agradecia e tecia comentários sobre o romance Exaltação da escritora Albertina Berta (aliás, atitude cultivada durante toda a vida para com os novos, sempre emitindo suas sinceras e honestas opiniões), escreveu que o que havia de pessoal em seus pobres livros interessava a muita gente. Isso após ter dito, três linhas antes, que nunca se sentava à sua modesta mesa para escrever pensando só em si, mas também nos outros. 13 Lendo o depoimento de Lima Barreto, não há como não pensar no artista idealizado por Tolstói, cuja criação não seria dirigida para a conquista de méritos individuais, mas sim acessível à maioria, transmitindo sentimentos que promovessem a união fraterna entre os homens.

Lima Barreto tornou-se escritor não por acaso, pois teve chance de seguir outro caminho profissional, haja vista ter sido estudante de engenharia na Escola Politécnica no Rio de Janeiro. A decisão de sê-lo, um ato de livre escolha, não foi ancorada apenas na vontade de revelar aos outros aquilo que ele via com muita clareza, a miséria da existência humana, mas também na decisão de expressar-se de uma maneira determinada, indicando uma clara ruptura com toda a retórica e erudição ocas reinantes na literatura produzida pelos seus contemporâneos. Nesse sentido, então, Tolstói foi para Lima Barreto muito mais que um escritor universal e obrigatório. ${ }^{14}$ Tendo-o como uma de suas bússolas, adotou, na elaboração de seu projeto literário, o ideal artístico ofertado pelo "profeta" de Yasnayá Polyana 15. De todos os ensinamentos colhidos em Tolstói, a sinceridade como condição essencial da arte foi lição jamais esquecida. Está presente desde o artigo de apresentação da revista Floreal'6, em que afirmava não se tratar de "uma revista de escola, de uma publicação de 'clã’ ou maloca literária":

Não se destina pois a Floreal a trazer a público obras que revelem uma estética novíssima e apurada, ela não traz senão nomes dispostos a dizer abnegadamente as suas opiniões sobre tudo o que interessar a nossa sociedade, guardando as conveniências de quem quer ser respeitado.

13 BARReto, Afonso Henriques de Lima. Obras completas. São Paulo: Brasiliense, 1956, 16, 17 v., t. I, p.284. 14 Antonio Arnoni Prado, em seu Lima Barreto: o crítico e a crise (Sāo Paulo: Martins Fontes, 1989) considera Tolstói "um dos grandes paradigmas de Lima Barreto".

151. Aldeia russa da província de Tula onde nasceu Tolstói. 2. Nome da revista editada por Tolstói 16 A revista Floreal foi lançada em outubro de 1907 e teve apenas quatro números. Projeto de um grupo bastante diversificado, tinha como alma Lima Barreto, que publicou na de número um o primeiro capítulo do romance Recordaçōes do escrivāo Isaías Caminha, e sendo por isso citado nominalmente pelo crítico José Veríssimo em artigo muito simpático à iniciativa, publicado na Revista Literária suplemento do Jornal do Commercio em 9.2.1907. 
É uma revista individualista, em que cada um poderá, pelas suas páginas, com a responsabilidade de sua assinatura, manifestar as suas preferências, comunicar as suas intuições, dizer seus julgamentos, quaisquer que sejam. [...] Temos grandes dúvidas, insisto mas não tantas que façamos residir toda a grandeza da literatura, todo o seu alcance e destino superiores, em rutilantes crônicas duvidosamente impressionistas ou no desenvolvimento em conto de anedotas da folhinha Laemmert".17

até os escritos da maturidade, como em "Amplius" 18 de 1916, no qual, respondendo a críticas sobre seu romance Triste fim de Policarpo Quaresma, reafirma seus ideais estético-literários:

Parece-me que o nosso dever de escritores sinceros ${ }^{19}$ e honestos é deixar de lado todas as velhas regras, toda a disciplina exterior dos gêneros e aproveitar de cada um deles o que puder e procurar, conforme a inspiração própria, para tentar reformar certas usanças, sugerir dúvidas, levantar julgamentos adormecidos, difundir as nossas grandes e altas emoções em face do mundo e do sofrimento dos homens, para soldar, ligar a humanidade em uma maior, em que caibam todas, pela revelação das almas individuais e do que elas têm de comum e dependente entre si.

A literatura do nosso tempo vem sendo isso nas suas maiores manifestações e possa ela realizar, pela virtude da forma, não mais a tal beleza perfeita da falecida Grécia, que já foi realizada; não mais a exaltação do amor que nunca esteve a perecer; mas a comunhão dos homens de todas as raças e classes, fazendo com que todos se compreendam, na infinita dor de serem homens, e se entendam sob o açoite da vida, para maior glória e perfeição da humanidade. 20

Vimos que, para Tolstói, quanto mais capacidade de comunicação tiver, mais verdadeira será a arte, e, para que isso ocorra, um dos requisitos essenciais é a clareza com que são expressos os sentimentos do artista. Lima Barreto também tinha isso como um valor fundamental no seu processo criativo:

O meu correspondente acusa-me também de empregar processos do jornalismo nos meus romances, principalmente no primeiro.

17 BARRETO, Afonso Henriques de Lima. Op. cit., v. 13, p. 181-3.

18 Idem, v. 6, p. 29.

19 Ainda sobre o tema, disse o escritor: "A arte e a literatura são cousas sérias, pelas quais podemos enlouquecer - não há dúvida; mas em primeiro lugar, precisamos fazê-la com todo o ardor e sinceridade". (Idem, v. 13, p. 221) e, "sempre achei a condição para obra superior a mais cega e mais absoluta sinceridade. O jacto interior que a determina é irresistível e o poder de comunicação que transmite à palavra morta é de vivificar" (Idem, v. 14, p. 125).

20 Idem, v. 6, p. 33-4 
Poderia responder-lhe que, em geral, os chamados processos do jornalismo vieram do romance; mas mesmo que, nos meus, se dê o contrário, não lhes vejo mal algum, desde que eles contribuam por menos que seja para comunicar o que observo; desde que possam concorrer para diminuir os motivos de desinteligência entre os homens que me cercam.

[...] Tento executar esse ideal em língua inteligivel a todos, para que todos possam chegar facilmente à compreensão daquilo a que cheguei através de tantas angústias.21

Para reafirmar a ascendência do pensamento tolstoiano em Lima Barreto, dando maior visibilidade e crédito ao já dito, é bom esclarecer que o autor brasileiro, em diversos momentos de sua obra, faz referências nominais ao romancista russo. No romance Recordações do escrivão Isaías Caminha, confessa, através da personagem Isaías, que buscava nos grandes autores normas para o fazer literário, sendo Tolstói um dos primeiros a ser lembrado. Em Vida e morte de M. J. Gonzaga de Sá, lamentando a não existência entre nós de uma grande literatura "preocupada e angustiada com os destinos humanos", pergunta quando é que veremos aqui "um Dostoiéviski, uma George Eliot, um Tolstói - gigantes destes, em que a força da visão, o ilimitado da criação não cedem o passo à simpatia pelos humildes, pelos humilhados, pela dor daquelas gentes donde às vezes não vieram - quando?".22 No já citado artigo "Amplius", Tolstói aparece como um dos grandes mestres da literatura moderna, aconselha também a leitura de seus livros aos jovens que se iniciavam no ofício de escrever, como faz em carta a Jaime Adour da Câmara em 27.7.191923. Mas é na conferência "O destino da literatura" - de especial relevância, por se constituir numa espécie de "testamento literário"24, visto que escrita apenas um ano antes de sua morte - Lima Barreto sintetiza toda uma concepção de arte e literatura elaborada com coerência e sinceridade ao longo de sua vida. Feita para ser proferida na cidade paulista de São José do Rio Preto, por ocasião de uma temporada em companhia de seu amigo, o escritor e médico Ranulfo Prata, na cidadezinha de Mirassol, vizinha a Rio Preto, acabou não acontecendo porque a natural timidez de Lima gerou tamanho nervosismo que resultou na busca do lenitivo de sempre, 0 álcool. 25

Nela, ao iniciar a discussão sobre a teoria da arte, o primeiro a ser lembrado é Tolstói com "sua sólida e accessível obra - O que é a Arte?" 26 e, embora cite ao

21 Ibidem, p. 34-5.

22 Idem, v. 4, p. 133-4.

23 Idem, v. 17, T. II.

24 A expressão é de Francisco de Assis Barbosa, biógrafo de Lima Barreto.

25 A conferência foi posteriormente publicada na Revista Souza Cruz (Rio de Janeiro), out.- nov. de 1921.

Lima Barreto dialoga com a concepção de arte de Leon Tolstói -213 
longo da conferência teóricos da Arte, como os franceses Hippolyte Taine, JeanMarie Guyau e Ferdinand Brunetière, em favor de suas convicções, 27 a ascendência tolstoiana perpassa todo o texto. Discorrendo sobre a capacidade que a literatura teria de transformar as idéias, as regras, os preceitos, em sentimentos que pudessem ser incorporados pelo leitor, diz:

Mais do que nenhuma outra arte, mais fortemente possuindo essa capacidade de sugerir em nós o sentimento que agitou o autor ou que ele simplesmente descreve, a arte literária se apresenta com um poder de contágio que a faz facilmente passar de simples capricho individual, para traço de união, em força de ligação entre os homens, sendo capaz, portanto, de concorrer para o estabelecimento de uma harmonia entre eles, orientada para o imenso ideal em que se soldem as almas, aparentemente mais diferentes, reveladas, porém, por ela, como semelhantes na imensa dor de serem humanos. 28

Está claramente enunciada aí a noção de contágio artístico preconizada por Tolstói, que só é efetiva se o artista for sincero. Bom discípulo, Lima Barreto faz uma apaixonada declaração, sem o pudor daqueles que temem o ridículo:

Mais do que qualquer outra atividade espiritual da nossa espécie, a Arte, especialmente a Literatura, a que me dediquei e com que me casei; mais do que ela nenhum outro qualquer meio de comunicação entre os homens, em virtude mesmo do seu poder de contágio, teve, tem e terá um grande destino na nossa triste humanidade. 29

Nessa fonte, Lima Barreto seguramente bebeu. Afinal, nada mais tolstoiano do que as considerações derradeiras da que seria sua primeira conferência, bela e ainda atual explanação sobre o poder da Arte e da Literatura:

A arte, tendo o poder de transmitir sentimentos e idéias, sob a forma de sentimentos, trabalha pela união da espécie; assim trabalhando, concorre, portanto, para o seu acréscimo de inteligência e de felicidade.

26 Idem. Obras completas v. 13, p.57.

27 Ávido leitor, Lima Barreto ia seletivamente recolhendo dessas leituras aquilo que pudesse somar para a sua formação intelectual. Esse assunto está tratado de maneira mais abrangente no ensaio: "Vida em tempos escuros: as rebeldias de Lima Barreto contra idiotas teses racistas", de Zenir Campos Reis [Nossa América. Revista do Memorial da América Latina (São Paulo), no. 3, p. 32-8, jul.-ago. de 1990] e em minha dissertação de mestrado: Um dissidente na república das letras: as idéias libertárias em Lima Barreto [São Paulo: 1998. (Dissertação de mestrado em Literatura Brasileira) FFLCH — Letras, Universidade de São Paulo.]

28 Ibidem, p. 62.

29 Ibidem, p. 66. 
[...] Ela explicou e explica a dor dos humildes aos poderosos e as angustiosas dúvidas destes, àqueles; ela faz compreender, uns aos outros, as almas dos homens dos mais desencontrados nascimentos, das mais dispersas épocas, das mais divergentes raças; ela se apieda tanto do criminoso, do vagabundo, quanto de Napoleão prisioneiro ou de Maria Antonieta subindo à guilhotina; ela, não cansada de ligar as nossas almas, umas às outras, ainda nos liga à arvore, à flor, ao cão, ao rio, ao mar e à estrela inaccessível; ela nos faz compreender o Universo, a Terra, Deus e o mistério que nos cerca, para o qual abre perspectivas infinitas de sonhos e altos desejos.

Fazendo-nos assim tudo compreender; entrando no segredo das vidas e das cousas, a Literatura reforça o nosso natural sentimento de solidariedade com os nossos semelhantes $[\ldots]$.

Atualmente, nesta hora de tristes apreensões para o mundo inteiro, não devemos deixar de pregar, como for, o ideal de fraternidade, e de justiça entre os homens e um sincero entendimento entre eles.

E o destino da Literatura é tornar sensível, assimilável, vulgar esse grande ideal de poucos a todos [...]. 30

30 Ibidem, p. 67-8.

Maria Salete Magnoni é doutoranda em Literatura Brasileira na Universidade de São Paulo. 